УДК 316

$10.17213 / 2075-2067-2020-5-106-111$

\title{
СОЦИАЛЬНО-ИНВЕСТИЦИОННАЯ МОДЕЛЬ РЕГИОНАЛЬНОГО УПРАВЛЕНИЯ КАК ИНСТРУМЕНТ СОЦИАЛЬНО-ЭКОНОМИЧЕСКОГО РАЗВИТИЯ ТЕРРИТОРИИ
}

\author{
(C) 2020 г. В. В. Кривопусков ${ }^{*}$, Б. Б. Месхи \\ "АО «Главкосмос», г. Москва, Россия \\ **Южный федеральный университет, г. Ростов-на-Дону, Россия
}

Целью исследования является анализ системь детерминант в условиях перехода к реализации социально-инвестиционной модели.

Методологическая база исследования строится на концепциии структурно-функционального подхода (Т. Парсонс), неоинституционального (Норт) и деятельностно-активистского подхода к исследованию регионального управления.

Результаты исследования представляют возможность применения сочиально-инвестищионной модели в решении проблем регионального управления как инструмента сочиально-экономического развития территории.

Перспектива исследования заключается в возможности использования его основных положений и выводов в дальнейшей разработке проблем регионального управления в российском обществе.

Ключевые слова: региональное управление; сочиально-инвестииионная модель; соииально-экономическое развитие; территория.

\section{SOCIO-INVESTMENT MODEL OF REGIONAL MANAGEMENT AS A TOOL FOR SOCIO-ECONOMIC DEVELOPMENT OF THE TERRITORY}

\author{
(C) 2020 V. V. Krivopuskov*, B. B. Meskhi** \\ "JSC «Glavkosmos», Moscow, Russia \\ ${ }^{* *}$ Southern Federal University, Rostov-on-Don, Russia
}

The purpose of the study is to analyze the system of determinants in the conditions of transition to the implementation of the social and investment model.

The methodological basis of the study is based on the concept of structural and functional approach (T. Parsons), neoinstitutional (North) and activity-activist approach to the study of regional management.

The results of the study of the research present the possibility of applying the socioinvestment model in solving the problems of regional management as a tool for socio-economic development of the territory.

The prospect of the study is to use its main provisions and conclusions in the further development of regional governance problems in Russian society.

Key words: regional management; socio-investment model; socio-economic development; territory. 
Введение. Система регионального управления проходит путь перехода к трансформационному управлению, определения границ автономности действий в рамках сложившейся вертикально интегрированной системы управления в российском обществе. Система регионального управления, сталкиваясь с внутренними и внешними вызовами, является индикатором социокультурной модернизации. Сложившиеся социально-инвестиционные модели регионального управления в российском обществе не являются доминирующими, но задают вектор изменений в системе регионального управления, так как содержат перспективы включения новых механизмов управленческого воздействия, определяют выход за пределы прагматических задач и в условиях воспроизводства и развития человеческого капитала в регионах обретают проективный характер. Учитывая, что в системе регионального управления сохраняется «многоукладность», совместимость традиционных административно-правовых и социально-инвестиционных регуляторов, можно сказать, что в контексте исследования социально-инвестиционной модели регионального управления в российском обществе важным является выделение основных и фоновых критериев (определение эффективности социально-инвестиционной модели регионального управления на основе структурных, организационно-нормативных, функциональных и деятельностных индикаторов).

Детерминация социально-инвестиционной модели в управлении российскими регионами. Теоретическое осмысление исследования социально-инвестиционной модели регионального управления уходит корнями в классическую социологию управления (концепции фордизма, школы человеческих отношений) с учетом того, что схемы регионального управления отличаются от управления организациями не только количественными параметрами (масштабами), но и включением механизмов управленческого воздействия, связанных с пониманием региона как социума, содержащего автономные структурные, институциональные и субъектно-деятельностные параметры. Структурно- функциональный [6], неоинституциональный [5], деятельностно-активистский подходы [3, $9,10,11]$, различаясь исследовательскими принципами и процедурами, ориентированы на анализ и объяснение социально-инвестиционной модели регионального управления в контексте изменений, связанных со сферой регионального управления. Можно констатировать, что в нынешней ситуации, учитывая переход к трансформационному управлению, на основе интегрирования объективных (структурных) и субъективных (деятельностных) условий регионального управления социально-инвестиционная модель регионального управления, испытывая воздействие концепции человеческого капитала и интерпретацию регионального управления как совокупности управленческих воздействий, осуществляемых субъектами управления (управленческими структурами и общественными ассоциациями), делают востребованной многомерную модель исследования, анализирующую развитие системы регионального управления в контексте получения знания о формирующемся региональном социально-экономическом пространстве. Это означает, что анализ системы регионального управления связан с установлением взаимосвязи процессов через «социальный поворот» в региональном управлении, фиксирующий взаимосвязь изменений в системе регионального управления и развитие регионального социума.

Специфику регионального управления в российском обществе можно охарактеризовать «гибридностью» управленческих моделей как инструментов достижения управленческих решений, что предполагает обращение исследователя к анализу тенденций в развитии регионального управления, наиболее полно проявляемых в становлении социально-инвестиционной модели управления, которая из сферы «идеальности» трансформируется в практические действия. На основе концепций неоинституционального и структурно-деятельностного анализа под региональным управлением понимается система действий и взаимодействий субъектов, включенных в систему регионального управления и обладающих социальной ресурсностью и профессиональной компетентностью, а также организационными навыками и опы- 
том в рамках воздействия на социальные и социально-экономические процессы в региональном пространстве.

Социально-инвестиционную модель регионального управления следует интерпретировать как совокупность методов, приемов, способов, позволяющих в процессе управленческого действия и взаимодействия в региональном пространстве проектировать и реализовать программы социально-инвестиционного развития региона.

Развитие социально-инвестиционной политики и переход к региональному социуму коллективного социально-инвестиционного развития. В российских регионах существует запрос на выравнивание социально-территориального неравенства независимо от конкретной конфигурации человеческих ресурсов. Однако можно только догадываться, каким образом это может происходить, учитывая различия регионов по социально-экономическому, социальнодемографическому и интеллектуальному потенциалу. В рамках образования «суперрегионов» - федеральных округов дифференциация между регионами проявляется еще отчетливей, так как соседство регионов с высоким уровнем социального развития и регионов с застарелыми социальными проблемами еще более усиливает межрегиональные различия.

Здесь есть повод для размышления, что является приоритетным в выстраивании социально-инвестиционной модели регионального управления: структурные, институциональные или деятельностные критерии. Поиск новых и сохранение существующих управленческих механизмов внутри российского общества и их взаимодействие с государственными структурами - это фактически поиск возможностей для выстраивания новой системы региональной иерархии [7]. В России этот вопрос предпочитают не ставить и не обсуждать открыто. Неявным образом социально-инвестиционная модель регионального управления понимается как возможность возникновения и развития социальных инвестиций, при этом критерии оценки механизмов реализации не обсуждаются. Также слабо выявлены ориентиры и задачи регионального управления в сфере регулирования и обеспечения социально-инвестиционного развития.

Исходными являются минимальные социально-инвестиционные стандарты, нормальные и допустимые при условии, что региональное управление принимает де-факто накопленные человеческие ресурсы, не подвергая сбоям сложившиеся механизмы управленческого воздействия. Проглядываются перспективы взятия регионов под опеку крупными государственными структурами практически в условиях существования в России государственного капитализма, но этот процесс нельзя считать экстраполируемым, так как ожидания от внедрения смешанной модели не могут быть высокими.

Российское государство гарантирует минимальную социальную поддержку и обязательность участия регионов в федеральных целевых программах. Госкорпорации руководствуются иными экономическими критериями, и навряд ли можно ожидать, что их усилия будут направлены на безвозмездное социального шефство. Вопрос состоит в том, что ожидания прихода на российский рынок новых мощных игроков (транснациональных операторов) также не оправдывает ожиданий. Серьезное изменение конкурентной ситуации актуализирует выживание российских игроков. Делая запланированные убытки, работая с предельно низкой рентабельностью, зарубежные игроки не становятся социальными резидентами, и их интерес к человеческим ресурсам региона ограничивается критериями дешевизны и профессиональной подготовленности.

Учитывая, что большинство транснациональных игроков связаны с привлечением массового низкоквалифицированного труда, а узкий слой специалистов формируется из экспатов, человеческий капитал региона не становится привлекательным. Это означает, что для анализа перспектив становления и формирования социально-инвестиционной модели регионального управления в российском обществе формируются несколько уровней критериев. Один из них связан со сложившимися моделями взаимодействия федерального центра и региона, с институциональными факторами и условиями институциональной среды. 
Такая позиция имеет основания, так как социально-инвестиционная модель регионального управления предполагает систему формальных и неформальных норм регулирования и саморегулирования управленческой деятельности, задающей определенный набор целей и приоритетов регионального развития. При этом следует отметить, что институциональные факторы строятся на основании развития институтов взаимодействия с федеральным центром.

Региональное управление в российском обществе основано на административной модели, где маловероятна позитивная социально-инвестиционная активность. Однако данные развития регионов свидетельствуют о том, что наблюдается тренд социально-инвестиционной деятельности вне описываемых ранее корпоративной и государственной моделей инвестиционной политики. Для прояснения сущности проблемы следует сказать, что в условиях моносубъектности регионального управления, неизменности институтов и моделей социального действия критерий институциональности определяется не только исследованием формальных и неформальных норм, практик формальных и добровольных соглашений. Важное место занимает социально-раздаточная матрица [1]. Важно выявить критерии векторности социальной политики в системе регионального управления: точечные, субсидиарные или общественно-служебные.

Таким образом, для исследователя данной проблемы важным становится определение параметров действующей корпоративной модели социального инвестирования, когда конкуренция в сфере обеспечения социальными услугами остается на нулевом уровне. Дилемма «административный ресурс - конкурентные отношения» [2] включает рассмотрение социально-инвестиционной модели в рамках сложившихся авторитарных и полуавторитарных принципов. При таком понимании можно констатировать, что институциональные изменения под влиянием государства или крупного бизнеса не приводят к эффективной социально-инвестиционной политике.

Если отвлечься от разговоров о бюрократизации регионального управления, от правил управленческого поведения, внутри- управленческих отношений и институтов контроля за реализацией управленческих задач, то исследовательским трендом остается определение функциональности регионального управления в развитии социальноинвестиционной модели. Здесь исследование наталкивается на проблему разграничения дисфункциональности и функциональности, поскольку еще Р. Мертон отмечал, что наблюдаемая дисфункциональность в реальности является реализацией институтами латентных (скрытых) функций.

Важно понимать, что социально-инвестиционная модель регионального управления является нормативной, в то время как сложившиеся управленческие отношения определяются эффективностью и сплоченностью управленческой команды, границами для персонального подбора, «сословными» ценностями. Необходимым условием реализации социально-инвестиционной модели регионального управления следует считать характеристику потенциала регионального управления на уровне имплементации таких инструментов, как организационный и кадровый ресурсы, сформировавшиеся модели управленческого поведения.

Заключение. Определение коридора возможностей социально-инвестиционной модели регионального управления означает, что требуется анализ конкретных управленческих решений, позволяющих осуществить эмпирическую идентификацию реалий социально-инвестиционной активности. Заявленные исследовательские позиции связаны с деятельностно-активистской парадигмой, и в этой связи следует еще раз обратить внимание на характер взаимосвязей между институтами управления и региональным социумом. Следует указать, что в рамках деятельностно-активистской концепции развертывается механизм воспроизводства социально-инвестиционной активности, где важно указать, как выстраивается и закрепляется иерархия представлений о социальноинвестиционной активности в региональном управлении.

Здесь, как представляется, важно определить функционирование институциональной среды, регулирующей экономическую и социальную жизнь регионального социу- 
ма. Представляется полезным рассматривать социально-инвестиционную модель регионального управления не в качестве стабильно воспроизводимой, а как перманентную трансформацию, процесс изменений, вносимых по мере совершенствования системы регионального управления. В основе этой аргументации лежит вполне реальная потребность системы государственного управления по возрождению человеческого потенциала, накопленного в предшествующий период для сильного модернизационного рывка в российском обществе.

В рамках исследования создание работоспособной объяснительной схемы связано с учетом тенденций рационализации деятельности институтов регионального управления для устойчивого функционирования социально-инвестиционной модели в региональном социуме и значимости коридоров возможностей, опирающихся на реалистичную тенденцию в развитии модели социального действия [2]. В этой связи важно охарактеризовать параметры социально-инвестиционной модели регионального управления как многомерный аналитический конструкт, включающий анализ и объяснение социально-инвестиционной модели регионального управления как совокупности управленческих действий и взаимодействий, направленных на рост социальных инвестиций, как инструмент повышения эффективности регионального управления, целями которого является устойчивое развитие региона через повышение качества человеческого капитала.

Необходимо изучение функций социально-инвестиционной модели регионального управления как управленческих воздействий, ориентированных на воспроизводство системы регионального управления и становление новых социальных реальностей в региональном социуме. Важным представляется определение кадрового потенциала регионального управления в соответствии с готовностью к реализации социально-инвестиционной модели управления. Можно сказать, что социально-инвестиционная модель управления в российском обществе фиксируется в рамках описания «реальности» и содержит диагноз относительно качественных изменений в системе регионального управления, свя- занных с «преодолением» прошлого опыта сугубо административного регулирования и необходимости переустройства институциональных структур регионального управления и деятельностно-мотивационной сферы субъектов регионального управления.

\section{Литература}

1. Бессонова О.Э. Раздаток: институциональная теория хозяйственного развития России. - Новосибирск: ИЭиОПП СО РАН, 1999. - 152 с.

2. Дискин И. Россия, которая возможна. - М.: Юрист, 2011. - 175 с.

3. Журенков К. Переезд власти // Огонек. - 2018. - №9. - С. 18-20.

4. Норт Д., Уоллис Джс., Вайнгаст Б. Насилие и социальные порядки. - М: Институт Гайдара, 2011. - 480 с.

5. Парсонс T. Система современных обществ. - М., 1998. - 270 с.

6. Пути России: существующие ограничения и возможные варианты. - М.: Наука, 2004. - 248 c.

7. Beck U. Risk Society Revisited. - L., 2007. - 173 p.

8. Giddens $A$. The Politics of Climate Change. - Cambridge: Polity Press, 2009. $126 \mathrm{p}$.

9. Urry J. Mobilities. — Cambridge: Polity Press, 2008. - 344 p.

\section{References}

1. Bessonova O. Je. Razdatok: institucional'naja teorija hozjajstvennogo razvitija Rossii [Razdatok: institutional theory of economic development in Russia]. — Novosibirsk: IJeiOPP SO RAN, 1999. - 152 p.

2. Diskin I. Rossija, kotoraja vozmozhna [Russia, which is possible]. — Moscow: Jurist, 2011. - 175 p.

3. ZhurenkovK. Pereezd vlasti [Moving power]// Ogonek. — 2018. —№9. — Pp. 18-20.

4. Nort D., Uollis Dzh., Vajngast B. Nasilie i social'nye porjadki [Violence and social orders]. - Moscow: Institut Gajdara, 2011. $480 \mathrm{p}$.

5. Parsons T. Sistema sovremennyh obshhestv [System of modern societies]. - Moscow, 1998. - $270 \mathrm{p}$. 
6. Puti Rossii: sushhestvujushhie ogranichenija i vozmozhnye varianty [Ways of Russia: existing restrictions and possible options]. Moscow: Nauka, 2004. - 248 p. 7. Beck U. Risk Society Revisited. - L., Press, 2008. — 344 p. 2007. $-173 \mathrm{p}$.
8. Giddens $A$. The Politics of Climate Change. - Cambridge: Polity Press, 2009. $126 \mathrm{p}$.

9. Urry J. Mobilities. - Cambridge: Polity

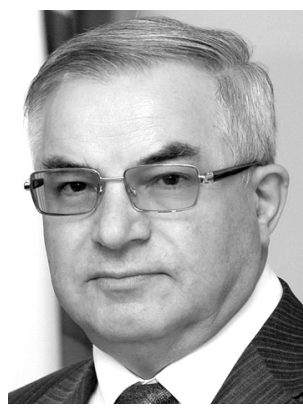

Кривопусков Виктор Владимирович - доктор социологических наук, советник Генерального директора АО «Главкосмос», видный общественный деятель, председатель Российского общества дружбы и сотрудничества с Арменией, член Генерального Совета и руководитель Комитета «Космос - пространство мира, доверия и сотрудничества» Ассамблеи народов Евразии.

Krivopuskov Viktor Vladimirovich - Doctor of Sociological Sciences, Adviser to the General Director of Glavkosmos JSC, prominent public figure, Chairman of the Russian society for friendship and cooperation with Armenia, member of the General Council and head of the Committee «Space - space of peace, trust and cooperation» of the Assembly of Peoples of Eurasia.

129110, г. Москва, ул. Гиляровского, 39, стр. 3 39 Gilyarovskogo st., bld. 3, 129110, Moscow, Russia

E-mail: rossotram@gmail.com

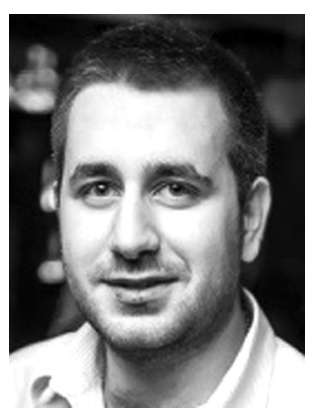

Месхи Бебури Бесикович - аспирант Института социологии и регионоведения Южного федерального университета.

Meskhi Bebury Besikovich - Post-graduate Student, Institute of Sociology and Regional Studies, Southern Federal University.

346500, г. Ростов-на-Дону, ул. Пушкинская, 160

160 Pushkinskaya st., 346500, Rostov-on-Don, Russia

E-mail: bebur9696@mail.ru 